\title{
It Makes Me Laugh: "What Makes Elderly Arab Women of the Acre Elderly Club Laugh?"
}

\author{
Janan Faraj Falah" ${ }^{1,2}$ \\ ${ }^{1}$ Sakhnin Academic College, Sakhnin, Israel \\ ${ }^{2}$ Western Galilee College, Akko, Israel \\ Email: Jananf81@gmail.com
}

How to cite this paper: Falah, J. F. (2020). It Makes Me Laugh: "What Makes Elderly Arab Women of the Acre Elderly Club Laugh?" Journal of Service Science and Management, 13, 281-298.

https://doi.org/10.4236/jssm.2020.132018

Received: March 16, 2020

Accepted: April 13, 2020

Published: April 16, 2020

Copyright $\odot 2020$ by author(s) and Scientific Research Publishing Inc. This work is licensed under the Creative Commons Attribution International License (CC BY 4.0).

http://creativecommons.org/licenses/by/4.0/

\begin{abstract}
This paper examines the importance of humor in the life of the elderly Arabic women. The Arab sector in Israel in general and in the city of Acre in particular has experienced many changes since the establishment of the State of Israel. Modern living has entered the Arab society and affected the structure of the extended and the nuclear Arab family. The increase in education level had led to integration in work both by Arab men and by women. In comparison to Western society, which emphasizes self-fulfillment, personal development and happiness, the Arab society, on the other hand, emphasizes the collective and harmony of the individual in relation to one's cultural and historical origin and surrounding. Welfare authorities in Israel provide varied services for the elderly; one of the most common services is the elderly day care centers, which have evolved greatly in the last decade. These centers provide social and therapeutic frame, meeting the elderly wide range of needs in order to preserve the social and economic independence of the elderly generation. These kinds of centers have evolved significantly also in the Arab sector, creating social supportive frame for the Arab seniors mentally and socially. These senior centers that rather been called "second home" have become big community centers both for elder and young people foe joint activity such as: workshops, teaching and touring. For the young generation, it is a platform for aiding the community and volunteering, in fact, it has become the most popular place for volunteering, and thus, makes the center more fascinating and intriguing. This research examines what makes elders laugh and the manner it is expressed in their life, through the qualitative method of researching, by semi-structures interviews at the Senior Center in Acre, in order to examine the phenomenon in depth.
\end{abstract}

\section{Keywords}

Elderly Women Center, Humor, Israeli Arabs, Arab Society, Seniors Day Club 


\section{Introduction}

The status of elderly people in the Arab society is affected greatly by the structure of the traditional family. Over the years, it was common that the family was a socially cohesive unit, both in terms of residence and economically. The extended family lived under one roof or nearby houses, and the assets, especially the land and property, the financial basis of the rural society, were owned and registered by the name of the head of the family-the father (Masarwa, 2008; Azaiza \& Croitero, 2010). At most cases, the daughters do not stay beside their parents, due to Arab norms and traditions that support women to "follow their husbands", to leave home and to move to their husbands. This had created an economic dependence of all family members on elderly parents, including the married sons and their children, and the elderly had substantial economic and social power. Due to the status of the elderly and the physical geographical closeness to their sons and their grandchildren, the care of the elderly was in the responsibility of family members, who were used for it whenever it was needed. The fact that the Arab family (mainly Muslim) has many children had made the task easier, for the responsibility was shared between great numbers of descendants. Thus, the elderly members of the family remained in their homes, and it was not customary to send them to nursing care. Furthermore, sending the elderly to a nursing home was perceived as neglect and betrayal in the Arab traditional society which embraces family values (Azaiza \& Croitero, 2010).

In recent years, this traditional perception has been changed. Family members are no longer seized as the sole care-takers of the elderly in general; especially in cases the elderly is limited. At the same time, the increasing acceptance and the ability to use formal services have also changed the common traditional perception. This change is emphasized mainly in the establishment of day care centers in the Arab villages.

The research literature on the subject of humor and its impact on elderly Arabs is very poor, mainly focuses on the elderly Arabs and their family. Thus, the findings of this research contribute to the subject, for it focuses on the subject of humor and its effect on the elderly specifically.

The aim of this study is to examine the importance of humor in the life of the elderly Arab women.

\section{The Arab Society in Israel}

Israel's Arabs constitute about one-fifth of the population of Israel. It is an ethnic-national minority with unique characteristics, not in the general ordinary sense of minority, for it had become a minority in its own native land, rather than being one by immigration to a foreign land. In terms of national-ethnic identity, the Arab minority is torn between the desire to socialize and being involved in the Israeli society, and its ethnic-Arabic nationality, a situation which intensifies the difficulty to socialize (Azaiza et al., 2009). The Arabs live in a 
country whose culture, customs, language, norms and national identity differ from their own. This group has experienced far-reaching modifications in various aspects of life, including in its social and family structure, financially and in terms of employment, education and living standards (Masarwa, 2008). The traditional values and norms which have dominated the Arab society had been evacuated for the benefit of modernization, as a result of the encounter with the Jewish society. Thus, from a rural population of farmers and Bedouin with poor national and social conscious, the Arab population became a modern one, with coherent nationality and better education, with distinct processes of social bonding. The exposures of the rural traditional community to mass media, alongside with the forming intensive relations with the urban society, are two vital elements in the course of the process (Masarwa, 2008; Azaiza, et al., 2009).

The processes of modernization on the Arab community in Israel have affected its social structure. This change is emphasized by the formation of new social layers that cultivate new characteristics such as: wealth, education, social prestige and other unique elements of social status, and enables social mobility from one status to another, mobility made possible by the principles of a democratic state (Azaiza et al., 2009).

The Arab community holds different social codes, not necessarily in comparison to the Jewish society, but in terms of its own. Thus, the rate of women participation indicates of their social status. It is important to note that urbanization and modernization processes that the Arab Society experiences for the last decades are slow, hence, large groups in the population, especially among women, maintain traditional life style in many aspects.

It is important to emphasize the changes among the Arab women, which became more educated, holding careers and becoming effective and essential partner at home, equal to their husbands. In 2015, the rate of employment among Arab women was $31.5 \%$ compared to $76.7 \%$ participation rate in the Jewish sector. Although the participation rate of Arab women in labor was slower than among Jewish women, a gap which has further expanded, different studies prove that the rate of participation among Arab women is affected by inner processes, within the Arab society itself, in relation to religion or ethnic origin. In fact, there are other factors that affect the rate of participation in the labor market as academic background, proximity of the village to Jewish employment centers, or living in mixed communities

At this phase it is important to emphasize the importance of mixed community, for its Arab population (women) is more educated and the rate of participation in the labor market is higher. Furthermore, these cities enable women to work, for there are more day-care centers and kindergartens.

These modifications have affected the extensive Arab family with its typical unified characteristics in the period of the pre-establishment of Israel, to become a nuclear family with unique, not unified characteristics, with a direct impact on the status of its seniors (Masarwa, 2008; Azaiza et al., 2009). 


\subsection{The Status of the Elderly in the Traditional Arab Society}

Before the establishment of the state of Israel, the elderly Arab had a central role in the rural, traditional and patriarchal society, financially, socially and politically. At that period, the nature of the Arab society was of an extended family, a "Hamula" (a clan). The family was the basic social unit financially and by terms of assets and accommodation (Azaiza; Croitero, 2010). The elderly were the head of the clan, the owners of the property and land, in fact, the whole village was consisted of one or several clans, and the family members worked under their supervision and order. For centuries, the elders ruled the village, their house-"Dewan" was the meeting place for elders and guests. The rest of the elders in the clan were members of the Elders Council, which had assembled at the elderly head of the clan's house to rule in various issues (Azaiza \& Brodizky, 1995). The head of the clan was chosen by natural courses rather than formal election. The age was an advantage, it did not affect the elder negatively, the more a person was aged, the greater his influence and impact was, the great impact was emphasized by ruling in all aspects of the extended family's life, both on its exterior public affairs against the authorities and other clans, and on its personal aspects of life. The elder in this traditional society was active until the end of his life: he was well familiar with the social and political systems, had connections, functioned as the representative of his family, and enjoyed the most distinguished status with the legitimation of his clan. His family was depended on him and had always sought for his advice. Alongside with one's financial, social and family hegemony, the Arab culture had also contributed to his distinguished elderly status and respect (Lowenstein \& colleagues, 1976 in: Azaiza \& Croitero, 2010).

The urbanization and modernization processes within the Israeli society have led to great changes in the social and family structure in the Arab village; require referring to the significant impact on the status of the Arab elderly.

\subsection{The Well-Being of the Arab Elders}

The data indicate that the elderly Arabs are poorer than the elder Jewish. Only $13.3 \%$ of the Arab elderly have pensions (in comparison to $45.4 \%$ in the Jewish sector), and their average pension is $70 \%$ of the average pension of Jews (Endblid et al., 2008). This situation reflects the earning capacity in the overall labor market, thus, an Arab employee earns $69 \%$ of the average salary of the Jewish employee, and the income per household is $65 \%$ of the Jewish household income.

The research findings examine the effect of the elderlies' economic plight on their well-being (Berg-Verman \& Brodesky, 2004).

The research focuses on four aspects: the quality of accommodation, feelings of loneliness, health condition: stress, and nutritional insecure. In all of these aspects, it is proven that financial difficulties lead to poor living conditions, and relatively large percentage of the elderly suffer from nutritional insecure, in comparison to the Jewish elderly population. In addition, this research indicates 
of the impact of the economic stress on health, thus, many of these problems are not been taking care of due to economic reasons. It is also effects the elderlies' ability to maintain family and social relations by will.

\subsection{The Use of Formal-Supportive Services}

The establishment of formal supporting services was at the period of Ottoman Palestine, later on, with the establishment of the state of Israel, the services were resulted in political, historical and social aspects, which had to face reality and to address the immediate needs of the population, rather than being a carefully planned policy, by the authorities. This unplanned policy is the basis for the outcoming policy over the years (Azaiza \& Croitero, 2010).

In the past, several factors had restrained the development of services in the Arab sector, one of these factors is the negative perception of the Arab elderly themselves and their families of using formal services, for traditionally, the responsibility for the elderly was on the family (Azaiza, Krotero, 2010). Another reason for this negative attitude was a former bad experience, sometimes due to a long wait for a service which did not even exist or was not developed properly, or unadjusted to the Arab population by means of language, religion and culture (Azaiza \& Brodesky, 1995). The attitude of the Arab elderly and their families towards the formal is a mixture of traditional and modern perceptions (Azaiza \& Brodesky, 1996).

There are two main elements to consider in examining the Arab elderly's acceptance of authorities' formal services; the first is, the extent of cultural adjustment of services to this population, avoiding of cultural barriers as in the Care Insurance Law, for instance, that hires the extended family to take care of the elderly, and thus, the family prevent the entering of an outsider caretaker into their homes (Lowenstein \& Katz 2000). The second aspect that should be taken into consideration is the balance between the family and the authorities' responsibility. On the one hand, the formal support should not exempt the family out of its responsibility; on the other hand, the neglected elderly who are denied of the care by their family should get the services and the support of the authorities (Azaiza \& Brodsky, 2003).

During the recent years, an elderly community services have been developed and established in the Arab elderly, "Eshel" organization, for example, an organization which strives to improve the status of the elderly population in Israel and to develop conditions and services to guarantee better quality of life for the elderly, with the support and cooperation with the Ministry of Social Affairs and local authorities (Azaiza \& Brodsky, 2003).

The community services (for elderly) provide services both to healthy functionally independent elderly and disabled ones. The services for the healthy independent elderly are done mainly by community centers and multi-service oriented centers, while the services for the disabled elderly are given in a day-care center (Yacovitz, 2003). The center serves as a social venue with varied cultural, learning, pleasant activities; the Multi-Service Centers on the other 
hand, provide a range of services to elderly who live within the community, such as medical, social, feeding, studying and leisure activities (Yacovitz, 2003). The Day Care Centers for the disabled elderly have evolved over the past decade and have number of goals. First, they provide social and therapeutic framework in order to meet the variety of needs and to maintain the functioning and independence of the elderly; Secondly, they are designed to encourage elderly to get out of their house, and thus, to allow the caregivers to rest a little. Every disabled elderly in Israel, who meets the functioning capacity conditions and the entitlement to a long-term care benefit by the State Law, is entitled for allowance (Enbled, 2008). The Care Insurance Law which was enacted in 1986 and enforced in 1988 provides pensions for elderly with daily disability to function. It is designed to maintain nursing aid at the elderly's home, household services and supervision (Yacovitz \& Nir, 2001). The percentage of elderly Arabs who receive Long Term Care Allowance, is higher than among the Jewish elderly population, probably as a result of the higher rate of disabled Arab elderly whereas the rate of established day carrying centers is lower (Azaiza \& Brodsky, 1996). This Law is a breakthrough for the Arab elderly population, for its presence and execution has increased the awareness towards the needs and difficulties of the elderly in the Arab society, both within the family and with the local authority. This awareness has encouraged the elderly and their family to claim their rights and facilitate the state in providing these services (Portugali, 2006).

Studies on the subject of elderly Arabs' extended stay in a nursing home are poor, due to the small number of needed elderly (Suleiman, 1998). The institutionalization rate of elderly Arabs in Israel is significantly lower than among Jewish elderly ( $0.7 \%$ vs. $4.1 \%)$ (Bar \& Brodsky, 2001). The studies indicate of several factors that create these poor rates in the Arab society. The first, refers to the Arab society collectivist orientation, both by social and family degrees, thus, consistent with society norms, accommodating the elderly parents in a nursing home is considered a shame. Lack of appropriate formal services adjusted to Arab culture is another factor for not using the formal services in general. A third factor is related to Islamic religion perception, in which, the offspring are obligated to nurse their parents at old age. Respectively, the Muslim Arab population already has extensive supportive network within the family, at the elderly's home (Khalaila, 2008). However, due to the changes in the Arab society, both by terms of family, the elderly status and women's status of employment and education, had led to abandon the traditional task of taking care of the elderly at home and to go working outside home, alongside with modification in the elderly's status, had required developing and creating of new institutional frameworks for elderly (Suleiman, 1998). It is common to argue, that the first nursery home in the Arab society was established in 1992 by the "Eshel Organization" in the village of Daburia. By data from 2006, there are over 10 nursing homes in the Arab population by private ownership, except for the one in Daburia (Portugal, 2006). For years, the informal family system was the sole supportive system available, yet, even now, it is still the main supportive one (Khalaila, 2008). 


\subsection{Characteristics and Needs among Elderly Arab}

Arab women in Israel are dominant by number, in the year 2007, the division by gender consisted of $46.8 \%$ men and $53.2 \%$ women. The vast majority of the elderly Arab men are married 87.2\%, while the average of Arab married women is merely $38.6 \%$ (by The Central Bureau of statistics, 2008), this gap is resulted primarily in the fact that women live more than men, and the social tendency to of Arab women to marry older men (Brodsky; Snor, \& Be'er, 2008). The same tendency was found in 2015, whereas 53\% of the elderly Arab population consists of 53\% elderly women and $47 \%$ of elderly men (CBS, 2015).

Miro and Haj-Yihya (2006) indicate that the Arab elderly in general and the elderly women in particular, suffer from many problems, mainly resulted in poverty, health and poor social relations. Naturally, loneliness, monotony and poor education contribute to low self-esteem and require solutions.

Elderly Arab women are more vulnerable to economic deprivatio-, due to the differences in labor in earlier ages (Ben-tor, Siteron, \& Chachamir, 2006). Although the perception of integrating working with family life is common in the Israeli society, gender inequality is very prominent in the Israeli labor market in various ways. One of the striking features is the low participation rates of women in the labor market, despite the percentage increase in education and the change in the status of the Arab woman in Israel. Moreover, many of the women work less hours, especially when their children are young. However, the inequality in labor is most prominent in the issue of wages, women earn less, not only due to the fact that they choose limited trades with relatively low-income, but also the fact that their low income affects their whole life, their state of health, conditions of accommodation and in means of family support (Bentor, Sitron, Chahamir; 2006). As a result of this gender equality, women's participation in the workforce is lesser than men's, evidently, by the time of retirement, their income is poorer than men's and they get less attention to their retirement and the issues involved with it (Bentor, Sitron, Chahamir; 2006). This approves the differences in experience and feelings between elderly Arabs men to elderly Arab women.

The issue of awareness to health is also unequal between elderly men and elderly women; women know less about their illness, are less updated and guided by their doctors regarding their health or how to maintain healthy lifestyle (osteoporosis, musculoskeletal diseases, hip fracture, and falling up, for instance). The lack of awareness is almost absolute among uneducated Arab women. Bentor, Stron \& Chahamir at Natur, siteron (2006) found that low percentage of elderly Arab women take care of visual impairment and hearing defects. The main reason for avoiding treatment is financial and due to physical disabilities that make physically difficult to arrive the clinic. Bolus (2013) in her study, examines the subjective experience of elderly Israeli-Arab women living in nursing-homes towards death and fearing of dying. The findings prove of differences in the extent of anxiety between the two groups of women, the one who lives within the community is more anxious of death and dying in comparison to the group living in a nursing-home. Khalaila (2008) specifies that elderly Arab women, 
mothers and senior mothers in law have a greater chance to receive medical treatment and social support from their children than the elderly fathers.

Simultaneously, physical abuse towards elderly Arabs within the family, had first began to occur, especially towards elderly Arab women who are the most vulnerable to abuse and neglect. Hence, the physical and sexual violence against elderly Arab women is higher; it is combined with restriction of freedom, prohibition of using the phone, locking the women at home and prevention of money. In addition, it was found that these women are twice as vulnerable as Jewish women (Izikowitz, Winter Stein, \& Lowenstein, 2005). Elderly Arab women with lower education are more vulnerable, and therefore, there is a need to maintain proper programs in order to meet their cultural special needs and to increase the participation of young and elderly women in the programs.

Participation in leisure activities is considered one of the most influential factors on a person's life quality.

\section{Leisure at Old Age}

Old age, similar to other age periods, can be meaningful, however, at the same time might be accompanied with feelings of emptiness, loss and bad taste. Indeed, aging means some limitations that an elderly have to accept, and many to cope with. Today, old age is perceived positively and appears to be desirable, despite its limitations and disadvantages (Dahan \& Nimrod, 2014).

Future seniors do not learn how to use their leisure time properly, thus, some of them age faster. This accelerated process of aging is followed by a sense of loss of self-esteem, of interest, curiosity, secure and becoming senseless (Nehushtan, 1980 in: Dahan \& Nimrod, 2014). Therefore, it is necessary to assist the elderly to find meaning to being free out of commitment", and to become committed to their spare time.

The prevailing opinion is that the aging process, at least theoretically, is related to reduce of leisure activity. Various life events such as retirement, a death of spouse, a decrease in mobility and the reduction in income - prevent the elderly from using properly their leisure time (Barzilai, 1995), thus, most of elderly people tend to engage in activities at home, such as watching TV, reading, or being occupied in household works, yet, these choices are not necessarily made by will or by preference, in fact, social related activities might lead to greater satisfaction. However, reality dictates, the accessibility to participate these activities is sometimes hard (Nicrog, 1996), therefore, these findings does not prove of elderly's passivity.

Horwitz (1992) declares that people in pre-retirement phase tend to "organize" their leisure time, deciding what social circle they will join, the particular club they will attend, learning and volunteering leisure activities they will-reading, watching TV, hobbies, etc. If this time of leisure is used properly, it will allow the elderly to develop positive relationship with society. Some researches are designed to examine whether leisure-time activities among elderly support and reinforce the fundamental significance which is attributed to these activities (of 
having fun, social gatherings, crafting, etc.).

Groney (in: Barzilai, 1995) have discovered a fundamental relation between participating in leisure activities and the sense of happiness among elderly. His research is based on four years collection of data from 60 elderly women. The research findings prove that participating in social activities as: visiting of friends, phoning and volunteering, are contributing for being satisfied. Another study, which examined the differences between elderly men and elderly women's experiences of aging, has found out that elderly women are more active, mainly in volunteering activities, and are more involved socially than elderly men (Openheimer, 1996).

Many studies prove that Arab pensioners' lack of leisure time is the most higher. In relation to other sectors, they poses the greatest motivation to participate in the activities, yet, a lack of available activities lead to this damage in needs, especially in terms of access to the Internet and computers, cultural activities, hobbies and volunteering. A thorough examination of the variety of leisure activities should be conducted, in order to develop a wider range of possibilities for this population (Dahan \& Nimrod, 2014).

\section{Theoretical Background}

\subsection{Laughter}

The concept "laughter" refers also to a "smile", which is considered laughing in a weaker degree of sound. There are five main sources that make a person laugh: laughing out of physical reasons, a mental need, laughing as a result of tickling, laughing out of extreme physical and mental conditions, and comic situation from (Sover, 2009).

Laughing improves the quality of life, revives positive emotions, and creates motivation, releases aggression and anger (Brant, 2008).

\subsection{Humor}

Humor is basically a social phenomenon, thus, we tend to laugh and joke frequently when we are gathered in a group, rather than being alone (Martin \& Kuiper, 1999). Games create a social bounding that lead to humor, communication is made by games and laughter expresses joy and mirth, for example, humor characterizes light, unserious atmosphere, in which, people say or do funny things (Martin, 2007).

A definition of humor is not an easy task; some claim that addressing the issue is a serious matter, an idea which stands in contrary with its "lighthearted" characteristics. Humor is usually defined in a gaiety, amusing mode (Zamir, 2007). Humor might be identified intuitively, thus, everyone recognize and feel humorous. Humor has been examined extensively in terms of science, both by the cognitive-social aspect of the personality and by psychoanalytical one (Rimor, 2010). Humor accompanies us from the day of birth, hence, it is an integral part of the child's development process, and according to psychoanalysis, children 
use it to release repressed emotions and aggressive impulses, actions which they already poses, thus, re-experiencing the sense of overcoming the difficulties in former developmental stages. In other words, the role of humor and laughing is to release extra energy and stress in the body, and to create a physical relief for the body from stress, confusion and distress. In the aspect of cognitive development, humor is developed in parallel to the child's cognitive development, therefore, children at the age of 2 to 4 years old are able to laugh at games which involve replacing of object (Kraus, 2014).

Sover (2011) refers to two types of humor, verbal and visual. Verbal humor is a function of the development of a spoken language, the visual one is considered relatively prior, thus, even infants use first the visual humor, before the verbal one. Visual humor appears in when the baby's age is six to eight months, then, few months later, the verbal humor begins. In addition, there are several types of humor, for example, a closing common humor that allow spouses to identify; it easily can get the opposite result. Self-humor allows facing a person's self-restrictions and traits tolerantly, thus, to prevents self-conflicts and guilt. Another type of humor is negative, leading to alliance and distanced relationships. Offensive humor is aimed to tease and insult a person, deepening the negative effect on the relationships (Levine Jacovy, 2013).

The other type of humor-the verbal one, requires higher cognitive and intellectual skills than the visual one, although, it should be noted that verbal humor has many different layers. The distinction between the types of visual humor is in relation to the extent of intellectual efforts a person has to invest to understand and reveal the humor's complexity. Understanding the verbal humor depends on a person's extents of language fluently (Language proficiency), general knowledge and cognitive skills. Evaluation of verbal humor also depends on behavioral and environmental elements (Sover, 2011).

Humor assists people in many situations. For example, humor has an important role in mental and physical stress, it allows coping with a problem by maintaining an "emotional distance", in order to divert a state of stress and anxiety. Occasionally, humor evokes new perception on social circumstances, and thus, improves the conditions and allowing different and new perspective (Rimor, 2010). Therefore, humor has become more and more common in the academia, lecturers and researches indicate that integrating humor in their lessons enhances the positive atmosphere and the intellectual pleasure in the classroom, leading to creative thinking, a strengthening of the teacher's position as the leader of his/her class. Moreover, humor in a classroom improves students' academic achievement and reduces the extents of stress and anxiety. Today, humor is used as a method of treating alienated teenagers, it assists them recognizing internal contradictions of mind, visualizing things differently, to control anxiety and to express their thoughts. This method with the teenagers allows the therapist to appear more human and less stiff or distant, it also enhances trust between the young patient and the therapist, another aspect or an angle to meet their problems, thus, leading to a better and safer exposing of feelings (Shemesh, 
1996).

\section{Methodology}

\subsection{The Research Method}

The current study examines the extent of humor in the lives of the elderly Arab women, who have lived throughout their lives in Acre, were housewives/housewrk or had temporary jobs. Therefore, this study was carried out by a qualitative method of research. The use of the qualitative approach enables studying the human experience without measuring the experience (Shkedi, 2003). It emphasizes the objects' experience rather than the objects' history, thus, highlights the objects' subjective interpretation in particular social reality (Tzabar Ben Joshuae, 2001).

\subsection{The Research Population}

The study includes interviewing 15 elderly Arab women between the ages of 67 to 79 , of which, 11 women are widows living with their children. They all were housewives with primary school education; only 4 of them had finished junior-high and had temporary employment and odd jobs. They all independent, participating the activities, they are all Muslim, speaking Arabic and Hebrew, and resident in the city Acre, they all have children. The elderly have been asked to measure the impact of humor on their lives, and how humor assists their conditions.

\subsection{The Research Tools}

The data are collected via interviews with elderly Arab women, as well as through observation (during their trip to the Golan Heights' Druze villages in the north of Israel). I choose to use the method of observation, for only by this manner I am able to track their behavior without diverting their attention, and thus, to enable them to act naturally and spontaneously.

\subsection{The Research Tools}

The research was conducted in the elderly Arab Day Care Club in Acre. 35 of the elderly Arab women between the ages of 62 to 80 attend regularly the Club, I chose for the research 15 women. I personally asked the women to participant the research, and I personally know them all, for I am a resident of the city and regularly lecture in the center. Furthermore, my students volunteer an hour per week at the club.

\subsection{Findings and Discussion}

In order to examine how laughter affects the life of the elderly Arab women in the research, the following questions have been asked:

1) What makes you laugh?

2) Does humor really assist meeting your needs, or is it merely to 'pass time', 
for everyone should be happy and with a sense of humor?

3) Does humor assist overcome obstacles or daily difficulties?

The interviews and observation have raised interesting findings:

\section{A. What does make elderly Arab women laugh:}

The question arises from the interviews is what causes seniors laughing. The qustions are varied, some describe past memories, as does 76 years old Anissa: "During the military rule, I was manipulating my mother in law only to avoid bringing her the water from the well of Khan-al Omadan, although we had water in our neighborhood, so I had said to her that I was afraid of the Jewish soldiers, it always worked, until she heard me telling her other bride how I manipulated her ..."

Some of the stories include amusing events at times of celebration, as Um Ali Zaida, 79 years old describes: “... I remember clearly to this day how Johara (my husband's aunt) was dressed on the day we drove to the village of Jadida bring the bride from the village ... she looked like a ghost".

Jokes regarding their presence, pains and ills, for instance (they laugh out of pain, to ease the stress and suffering), “... Two years ago, I had constipation ... it hearted so much that I had to go to the hospital and to make an enema ... I think the nurse who did it regrets the day she became a nurse ..." (Zbeida Um Muhamad, 73 years old).

Another interesting topic that make the elderly Arab women laugh is their grandchildren, for instance, Um Yusef Hiffa (74 years old) describes "when I speak with my grandchildren, especially the younger ones, I cannot understand them, their language is so complicated in addition to my hearing problems ... they talk about Spiderman, Barbie, Ironman, Spidey-Queen ... characters that did not exist in my time ... today, I speak English better than president Obama ..." There are some more varied activities that make them laugh, such as: the activity in the Club, gossip, "spend time" with the family, spend time with humorous people, the way fat people move, matching up the grandchildren's generation with their generation, family events, old comic plays in TV, worries, the Club's employees and volunteers, playing cards and winning their friends.

It is apparent that the elderly women manage to find in any event or place humor, and perceive humor, even in their age, as a kind of a getaway to ease and pleasant their time. Often, they get confused between humor to happiness, what makes them laugh and what makes them happy. It can be conclude that humor leads to happiness, and vice versa. Most of the laughing is done and made in the presence of family and friends.

This finding is reinforced in Rimor's study (2010) who finds out that humor enables coping. This coping is created by taking "an emotional detachment" in order to create destruction from stress. It also enables arranging contradictory thoughts, solving them from different angle that would enhance controlling the anxiety and expressing the emotions sagely and clearly (Shemesh, 1996).

\section{B. The use of humor meets various needs:}

1) The need to be in relations and be loved. 
2) The aggressive motive: I wanted to make people laugh.

3) The aesthetic motive: to make people nice.

4) A sense of satisfaction, pleasure, secure and feeling good.

The elderly women were asked to describe the impact of humor on their lives, the manner and nature of assistance, the role it has, except for making us laugh, why is it needed in our lives, and what is the role of humor in bonding people socially.

All the interviewees expressed positive attitude towards humor and its great importance in creating an optimistic attitude, being amused, have a clear 'light' perception of life, in order to face the difficulties. Thus, humor is not merely a tool; it is also an attitude, a state of mind.

"I'm looking for happiness and joy that I hadn't experienced, due to difficulties and hard time, and now in this age, it is time to relive, having fun, enjoy the moment and laugh" (Hajleh,, 73 years old).

According to Martineau (1972), laugh symbols the group secure, ables to continue enjoying each other's company without fearing. For the group, humor is a consensus, it bridges the gaps, and has an important role, especially in times of crisis and stress. Bergson (1988) argues that humor and laughing are mechanism of survival and defense in a person's life.

"I hate being lonely and love to spend time with people, to visit them, to play together in the Club, to discuss social issues, tell jokes... This is how time should be spend, with a group of people my age, where I feel loved, warmth, and most important fun, I $m$ socially accepted, $t$ is good for my soul' (Um Ramez, age 74 , a widow).

In addition, humor and laughter is a common language within the group. There are "private jokes" joint folklore which distinguishes the group from other groups. Humor has an important role for the elderly, for it assists them facing the growing problems and difficulties, the social injustice and the abusive and disrespecting attitude towards them.

"I love my children and my grandchildren, but I feel useless at home, my opinion does not count although they all show respect ... I go travelling only to forgett feeling weak and useless, in order to change my mood and atmosphere" (Radia, age 70, a widow).

"I think it's better to be in a place with people like you, in any aspect, only they would understand you, would feel the same as you, and even help you to live your life without waiting to death at any moment" (Huda, age 7, a widow).

A person is considered "old" not only by age, chronologically, but also by one's social, psychological and other standards of functioning, furthermore, some of the chronologically very old people still feel young, and some, in the early middle age already feel old.

The use of humor in old age improve communication with society, leading to becoming less lonely, enables taking a position of a bystander in facing inner difficulties, "fill up" time for fun and amusement, feeling good even if one's condition is inevitable (Cohen, 1994). 
"This is my golden age, not just mine but for all the old people, I feel younger than I was a teenager, $P \mathrm{~m}$ more flexible, smiling all the time, characterized as a woman with a sense of humor, taking care of people, making them laugh by tell jokes, share with the mall sorts of activities, for this is who I am, I rather see people happy in order to feel happy. Before, I had dedicated my life to my children, to provide all their needs, it's about time to ..." (Um Rabiea, age 75, a widow).

Due the importance of humor to a group, humoristic people are highly valued; their contribution to society is great, for they provide and meet its needs. All members of the group laugh where there is humor, some more and some less. All human beings, regardless their race, gender and geographical origin laugh.

"I fear death. In my age, it might surprise me any minute. This feeling stress and annoy me, they cause me great anxiety, and in order to avoid them, I use humor, For instance, participating trips, watching comedies ..." (Miriam, age 67, a widow).

Good sense of humor is a necessary; it is an efficient tool for mental health. Its contribution to mental health is primarily expressed by enabling a person to deal with conflict, stress, tension and anxiety, and leading to stress relief (Bar-Tur, 2005).

The desire to deny our age, combined with fearing of society attitude towards aging, the loss of direct relationships with people, and the need to release excessive energy at times of emotional stressful situations, leads humor to become a solution. Laughing is the manner for expressing excess energy and becoming once again mentally balanced. In this situation, laughing does not depend on special reason, for it, by itself, leads to enjoyment and satisfaction; it has a defense mechanism which reduces anxiety, aiding the elderly to cope and survive (Kris, 1967 in: Cohen, 1994). Laughing and crying are similar means to alleviate stress; the first derives from a sense of satisfaction and the other from the opposite (Shemesh, 1996).

"I always tell my grandchildren funny stories of my past, I want them to love me more and to become for them a source for pleasure" (Faitma, age 69).

A person imagines the comic mode out of past experience, from one's memory. Once again, remembering of the situation arouses the imagination. In order to create funny mode, one needs to remember all the details in the past, at time of the situation. We would laugh again from a comic scene we have seen in a movie, only if we remember all the exact details of the scene. In order to make our friend laugh too, we would have to describe the scene in detail (Sover, 2009: pp. 48-49).

"When I laugh with a group of people I feel pleasure, I get the opportunity to get a relief, to feel fresh and comfort" (Um-Salem) and "health, peace and tranquility are the basic elements for my joy and happiness" (Radia, age 70, a widow).

Humor and laughter have a strengthening healing power, an important role in maintaining our mental and physical health. However, the question is whether 
they are vital in coping traumatic events, as the Holocaust for example (Ostrover, 2009). The common denominator of all these satisfying pleasuring elements is the sense of secure they provide the person, laughing is a social gesture aiming to suppress radical actions, to ease and loosen rigidity restricted by society norms (Cohen, 1994).

C. The elderly interviewees are asked to describe the effect of humor on their lives, the manner and platform it assists them.

All the interviewees expressed positive attitude regarding humor, stating its great importance for them, essentially by initiating optimistic, amused mood, elevating their perception on life. They all said that humor assist facing their problems. All the participants agree that humor assists facing the problems.

"P $m$ looking for joy and happiness that I hadn't the chance to experience, due to my difficulties in the past, so, now it's the time at this age, to give a chance and reliving my life, to enjoy every moment, to laugh, to participate in activities and tours that make me happy, things that I would never experience otherwise" (Um Ahmed, age 70).

"I hate feeling alone, I love spending time with the women in our Club, to play games, to discuss different topics, to tell jokes ... this is how I should spend time, with a group of women my age, surrounded by their love and warmth, and most important, to smile and have fun" (Salem, age 74).

"... At my age, I fear death constantly, at might come any moment, by surprise, and it makes me anxious and emotionally stressful, I found my-self annoyed and depressed seeking way to avoid these feeling, through humor, for instance: participating excursions where I laugh a lot and tell jokes all the way in the bus, watching comedies on the TV' (Miriam, aged 67, a widow).

“... I always tell my grandchildren stories of my past, so they would love me better and would see me as their source for enjoy." (Fatima, age 69)

“... When I laugh with a group of women I feel pleasure, opportunity to relive my life, feeling fresh and pleasant.” (Um Salim, age 76)

It is apparent that humor has great role in the lives of the elderly women. It creates means to relief, solace, and escaping of their daily difficulties, for humor exposes them to a variety of positive aspects, despite their emotional and social difficulties-both generated by society and family. The daily activities at the elderly women day care center (and tours) provide them a kind of alternative, to maintain meaningful, fulfilled life against their daily harsh ones.

\section{A Summary}

Humor defines society boundaries of tolerance towards its values: aesthetics, language, knowledge and behavior. In order to be popular in society, the individual should adjust oneself to its norms, a person who denies these norms, is punished by the society by means of irony and critics, in order to alter the behavior (Cohen, 1994).

It is apparent that the elderly women manage to find in any event or conver- 
sation an opportunity to laugh, a tool to relief tension and stress from in their daily life. In addition, humor assists them in the social, aesthetic sphere, to release aggressions and to fulfill their needs.

The importance of humor is emphasized in our willingness to spent money and takes part in humoristic events and standups.

The research reveals that humor is a mean to reveal the elders' thinking and distress, to express personal experience and concepts, and to expose their uniqueness.

According to the findings, seniors greet laughter, they are fully aware that it is the sole platform to connect to society and family-children and grandchildren. Elderly Arab women use humor and age, to some extent, in order to deliver a massage gently, without hurting relatives and friends, or be offended by them either. The findings also prove that elderly women use humor to keep the family together. It is well known that the young generation constantly seek for changes and renovations, yet, the elderly women know how to adjust their needs by humor and laughter.

The study proves that senior women use humor in order to alter a mood, and most important, the research has proven that elderly women feel the change especially on days at the Club, passing the time by laughing and singing, as in opposite to days of staying alone at home.

This study has limitations that are related to the size and population-specific research used.

Suggestions for future research:

Continuing research could focus on the life of elderly women in Arab society in change of status and conducting research represents a heterogeneous population within that which allowed us to study the elderly population in the Arab sector and examine the changes.

\section{Conflicts of Interest}

The author declares no conflicts of interest regarding the publication of this paper.

\section{References}

Azaiza , F., \& Brodsky, J. (1996). Changes in the Arab World and Development of Services for the Elderly Arab in Israel during the Last Decade. Journal of Gerontological Social Work, 27, 37-53. https://doi.org/10.1300/J083v27n01 04

Azaiza, F., \& Brodsky, G. (1995). Changes in the Arab Family and the Development of Services for the Elderly in Israel in the Last Decade. Gerontology, 70, 69-80.

Azaiza, F., \& Brodsky, J. (2003). The Arabs of Israel's Aging Population; Existing Needs, Responses and Dilemmas of the Undevelopment Services for a Society in Transition. The Israel Medical Association Journal, 5, 383-386.

Azaiza, F., \& Croitero, T. (2010). A Change in the Status of the Elderly in the Arab Society. In Y. Barrick, \& A. Lowenstein (Eds.), The Elderly \& the Family. Jerusalem: Eshel.

Azaiza, F., Abu-Baker, H., Hertz-Lazarowitz, R., \& Ganem, A. (2009). Arab. 
Bar, S., \& Brodsky, C. (2001). The Elderly Population in Israel-The Extent of Disability \& Assessing of Specific Services: 1999-2010. Jerusalem: JDC Brookdale Institute.

Bar-Tur, L. (2005). Positive Mental Health in Aging and Old Age. Gerontology, 32, 113-127

Barzilai, A. (1995). Leisure Time in Nursing-Home. Polls \& Reviews in Gerontology, 95, 7-18.

Ben-Tor, N., Siteron, D., \& Chahmir, S. (2006). Elderly Women: Status, Needs \& Direction towards Improving of Life Quality. Jerusalem: Myers-JDC-Brookdale Institute.

Bergson, H. (1988). Laughter (Translated by Yaacov Levi). Jerusalem: Reuven Mass.

Berg-Verman, A., \& Brodsky, G. (2004). The Effect of Economic Plight on Elderly and Their Lives. Jerusalem: JDC Brookdale Institute.

Bolus, R. (2013). The Subjectivity of Elderly Arab Women Living in the Community or in Nursing-Home in Relation of Fearing Death through Questionnaires and Painting of Bridge. Arts Therapy: Research \& Arts, 3, 317-325.

Brant, G. (2008). “Laughing Is a Serious Business”: Medical Clowning for Clean Addicts. A Journal of Social Workers, 50, 41.

Brodsky, G., Snor, Y., \& Be'er., S. (2008). The Elderly in Israel-2007 Statistical Yearbook. Jerusalem: JDC Brookdale Institute.

CBS 2015 (2015). The Database Was Created with the Assistance of the Central Bureau of Statistics Israel, and Is Taken from the Following Datasets: Population Registry.

Cohen, A. (1994). Humorous Life, Humour Therapy in Practice. Haifa: Amazia.

Dahan, D., \& Nimrod, G. (2014). Leisure Patterns among Israeli Senior Citizens-The Ministry for Senior Citizens the Research Centre of Aging in Israel. Jerusalem: The Hebrew University.

Endbled, M. (2008). A Review for 2007. Jerusalem: The National Insurance Institute of Israel.

Endblid, M., Gottliv, D., \& Frumann, A. (2008). The Social Gaps \& the Extent of Poverty-2007: An Annual Report. The National Insurance Institute.

Horwitz, M. (1992). Each Age and Its Characteristics. Tel Aviv: Dvir Katzman.

Izikowitz, Z., Winterstein, T., \& Lowenstein, A. (2005). A Survey on the Abuse and Neglect of the Elderly in Israel-A Final Repor Phase 1. The Report Was Presented to 'Eshel'-The Association for Planning \& Development of Services for Elderly in Israel and the National Insurance Institute of Israel. Haifa: Haifa University, The Center of old Age.

Khalaila, R. (2008). Modernization and Dedication of Children to Their Elderly Parents in the Arab Society in Israel. Doctorate Paper, Jerusalem: The Hebrew University

Kraus Rozen, Y. (2014). Baby's Laugh: The Way Humor Develops in Children. Ynet 12.30 .

Levine Yacovi, A. (2013). Very Funny: The Effect of Humor on our Relationship.

Lowenstein, A., \& Katz, R. (2000). Arab and Families Coping with Rural Care Giving. Marriage and Family Review, 30, 179-197. https://doi.org/10.1300/J002v30n01 11

Martin, R. A. (2007). The Psychology of Humor: An Integrative Approach. London: Academic Press.

Martin, R. A., \& Kupier, N. A. (1999). Daily Occurrence of Laughter: Relationships with Age, Gender, and Type. A Personality. Humor: International Journal of Humor Research, 12, 355-384. https://doi.org/10.1515/humr.1999.12.4.355 
Martineau, W. H. (1972). A Model of the Social Functions of Humor. Goldstein J.H. https://doi.org/10.1016/B978-0-12-288950-9.50011-0

Masarwa, R. (2008). The Arab Middle Class: Educated Women as the Carriers of the Change. M.A. Thesis in Sociology of Education, Tel Aviv: Tel Aviv University.

Miro, \& Haj Yihya, A. (2006). An Olive Branch Integration between Arabs and Jews in the Elderly. The National Insurance Institute, Jerusalem.

Nehushtan, G. (1980). Leisure as a Development Factor in the Development of the Elderly. Gerontology, 15-16, 49-63.

Nicrog, S. (1996). The Elderly in the Community. Knowledge \& Working Principles, Jerusalem, Community Center company in Israel. Exhausted Elderly. Gerontology, 25, 119-126.

Openheimer, A. (1996). Perspectives on Old-Age Experiences: Differences between Men \& Women. Surveys and Reviews in Gerontology, 99, 26-27.

Ostrover, K. H. (2009). Without Humor We Would Commit Suicide. Jerusalem: Yad Vashem.

Portugali, A. (2006). Arab Nursing Homes in Israel. Gerontology, 33, 63-80.

Rimor, M. (2010). Humor-In Psychology and Society. Kaveret, 18, 25-29.

Shemesh, A. (1996). Treating Detached Teenagers with Humor. In From Detachment to Integration, Booklet 7.

Shkedi, A. (2003). Words Attempt to Reach. A Qualitative Research-Theory and Application. Tel Aviv: Ramot.

Sover, A. (2009). Humor for the Man Who Laughs. Jerusalem: Carmel.

Sover, A. (2011). Verbal Humor, Humor Online, Sheet 1 (pp. 15-25).

Suleiman, H. (1998). A Nursing Home for the Elderly Arab: Nursed Elderly via.

Tzabar Ben-Yehoshua, N. (2001). Traditions \& Trends in Qualitative Research. Tel Aviv: Dvir.

Yacovitz, A. (2003). Community \& Formal Services for Elderly. In A. Rosin (Ed.), Aging and Old Age in Israel. Jerusalem: Eshel.

Yacovitz, A., \& Nir, M. (2001). The Concept of Getting Help in Houseworks for Elderly Jews and Arabs with Nursing Allowance. Social Security, 60, 171-190.

Zamir, S. (2007). Integrating Humor in Teaching. The College of Management Academic Studies. 